\title{
Letter identity and visual similarity in the processing of diacritic letters
}

\author{
Sachiko Kinoshita ${ }^{1}$ (1) $\cdot$ Lili Yu $^{1} \cdot$ Rinus G. Verdonschot ${ }^{2} \cdot$ Dennis Norris $^{3}$
}

Accepted: 5 December 2020 / Published online: 19 January 2021

(C) The Psychonomic Society, Inc. 2021

\begin{abstract}
Are letters with a diacritic (e.g., $\hat{a}$ ) recognized as a variant of the base letter (e.g., a), or as a separate letter identity? Two recent masked priming studies, one in French and one in Spanish, investigated this question, concluding that this depends on the language-specific linguistic function served by the diacritic. Experiment 1 tested this linguistic function hypothesis using Japanese kana, in which diacritics signal consonant voicing, and like French and unlike Spanish, provide lexical contrast. Contrary to the hypothesis, Japanese kana yielded the pattern of diacritic priming like Spanish. Specifically, for a target kana with a diacritic (e.g., ガ,/ga/), the kana prime without the diacritic (e.g., カ, / ka/) facilitated recognition almost as much as the identity prime (e.g., ガーガ =カーガ), whereas for a target kana without a diacritic, the kana prime with the diacritic produced less facilitation than the identity prime (e.g., カーカくガーカ). We suggest that the pattern of diacritic priming has little to do with linguistic function, and instead it stems from a general property of visual object recognition. Experiment 2 tested this hypothesis using visually similar letters of the Latin alphabet that differ in the presence/absence of a visual feature (e.g., $O$ and $Q$ ). The same asymmetry in priming was observed. These findings are consistent with the noisy channel model of letter/word recognition (Norris \& Kinoshita, Psychological Review, 119, 517-545, 2012a).
\end{abstract}

Keywords Diacritics $\cdot$ Masked priming $\cdot$ Japanese kana $\cdot$ Noisy channel model

Recognition of a written word begins with the identification of letters that comprise the word. Research in the past decade has seen much advancement on understanding this "front-end" of reading (i.e., orthographic processing, the processing of letter identities and letter order; e.g., Adelman, 2011; Davis, 2010; Dehaene, 2009; Norris \& Kinoshita, 2012a). In this domain, as in investigation of other aspects of reading and language, it is important to move beyond English, the dominant language studied, and ask whether the representation/process in question is language-universal (see Frost, 2012, and the associated commentaries).

Supplemental material: The raw data and the output of the statistical analysis from this study can be found on the Open Science Framework (https://osf.io/6ahy7/)

Sachiko Kinoshita

sachiko.kinoshita@mq.edu.au

1 Department of Psychology and Macquarie University Centre for Reading (MQCR), Macquarie University, Sydney, NSW 2109, Australia

2 Hiroshima University, Hiroshima, Japan

3 MRC Cognition and Brain Sciences Unit, Cambridge, UK
Recently, Chetail and Boursain (2019) took an important step in moving beyond English in studying letter identification: They investigated whether letters with and without diacritics (e.g., $\dot{a}$ and $a$ ) - we will refer to these as $\mathrm{D}+$ and $\mathrm{D}^{-}$ letters, respectively — share the same, or separate orthographic representation. This issue has not received much attention to date because most of the work on letter recognition has been conducted in English, which is written using the 26 letters of the Latin alphabet, none of which contain diacritics. In contrast to English, however, many languages include letters with diacritics - within those written in the Latin script alone, French, German, Spanish, Czech, Finnish, Turkish, and Vietnamese, to name but a few; other scripts (Arabic, Japanese kana) also make extensive use of diacritics.

A diacritic is a mark added to a character to indicate a modified pronunciation. Protopapas and Gerakaki (2009) have pointed out that diacritics are used across different languages and for different linguistic purposes, encoding features ranging from segmental (phonemic) identity (as in French, German, Hungarian) to suprasegmental information such as stress assignment (as in Spanish, Italian, Greek) and tone (as in Vietnamese). Chetail and Boursain (2019) noted this diversity in linguistic function and suggested that a letter with a diacritic may be given a full and separate letter status when 
the diacritic can distinguish between two lexical entries, as in French (e.g., tache vs. tâche, meaning "stain" and "task," respectively), or when the letter variants with and without diacritics are given different letter names, as in Turkish.

Two recent masked priming experiments using the alphabetic decision task ("is the stimulus a letter?"), one in French (Chetail \& Boursain, 2019) and the other in Spanish (Perea, Fernández-López, \& Marcet, 2019), have been reported as supporting this view. Using vowel letters in uppercase without a diacritic (D- letter, e.g., $A, O)$ as targets, ${ }^{1}$ and lowercase letters as primes, Chetail and Boursain (2019) reported that the $\mathrm{D}+$ letter prime facilitated target recognition less than the identity prime did, and no more than a visually dissimilar unrelated control letter prime (e.g.,, $a-A<\grave{a}-A=z-A$ ). The authors took this as indicating that in French, letters with a diacritic are processed as separate letter identities from the base letter without a diacritic. Perea et al. (2019) conducted a similar experiment in Spanish, where vowel letters with accent marks (e.g., $a, e ́$ ) signal the stressed syllable without altering phonemic information and do not provide lexical contrast. Based on this difference in linguistic function, the authors hypothesized that unlike French, "one would predict that both e and é would activate the same abstract representations in Spanish" (p. 2). Perea et al.'s results partially supported this prediction. Perea et al. extended Chetail and Boursain's original experimental design, and in addition to the $\mathrm{D}-$ letters as targets, Perea et al. also tested D+ letters as targets. For these letters (D+ letters) as targets, the diacritic prime (i.e., D- letter prime) facilitated target recognition as much as an identity prime $(\dot{a}-\dot{A}=a-\dot{A}<e-\dot{A})$. In contrast, for letters without a diacritic (D- letters) as targets, Perea et al. found that the diacritic letter prime facilitated target letter recognition less than an identity prime, but more than an unrelated control prime $(a-A<\dot{a}-A<\dot{e}-A)$. Perea et al. interpreted these results as indicating that "unlike French, accented and nonaccented vowels in Spanish (e.g., é and e) can be considered as variants of the same abstract representations" (p. 7), attributing the differences between the two studies to the different linguistic function served by diacritics in French and Spanish. Note, however, that this conclusion is based mainly on the condition that was not tested in the original French study (target letters with a diacritic): For the target letter without a diacritic, both French and Spanish results showed that a diacritic prime produced less priming than an identity prime $(a-A<\dot{a}-A)$, but Perea et al. did not focus on this result. ${ }^{2}$

\footnotetext{
${ }^{1}$ In French, diacritics are typically omitted for uppercase letters.

${ }^{2}$ Another difference between French and Spanish results was that for the targets without a diacritic, the diacriticked prime facilitated target recognition more than an unrelated prime in Spanish, but not in French. One factor that may be responsible for the discrepancy is the choice of letters used as the unrelated prime in the two studies (unaccented consonant letters e.g., $\mathrm{z}-\mathrm{A}$ in the French study and accented vowel letter e.g., é-A in the Spanish study). We will return to this issue in the discussion of Experiment 1.
}

In sum, there are two outstanding questions with current research on diacritic priming. One is that, as noted above, Chetail and Boursain (2019) did not test letters with a diacritic as targets, so it is not known whether there is a real difference in the pattern of priming in languages in which diacritics serve different linguistic functions. That is, the linguistic function hypothesis has not been put to a full test. Second, and more important, the linguistic function hypothesis does not explain the extant data fully: In particular, it is unclear how the asymmetry in diacritic priming observed within the Spanish stimuli can be explained in terms of the linguistic function. Perea et al. (2019) wrote that there are reasons to believe that accented vowels might be less effective as primes than nonaccented vowels are, but did not commit to an explanation. Of note, the authors raised the possibility that the diacritic mark in a prime stimulus represents a visually salient feature and "this could potentially limit its impact on the target stimulus as a function of whether or not this salient feature is also present in the target" (p. 2), but did not elaborate how this might work. (More recently, Perea, Baciero, \& Marcet, 2020, again appealed to the notion of salience to explain the pattern of diacritic priming; we return to this study in the Discussion of Experiment 2.)

The present study addresses these questions. First, we test the linguistic function hypothesis by using a script in which diacritics serve a very different linguistic function from accent marks on vowel letters in Spanish. As will be described shortly, the linguistic properties of letters with and without a diacritic in the Japanese kana syllabary indicate that they function as different letter identities As such, a clear prediction from the linguistic function hypothesis is that the Japanese kana should replicate the pattern of priming observed with French, but not with Spanish, with the facilitation produced by the diacritic prime (a prime differing from the target letter only in the presence/absence of diacritic) to be less than that produced by the identity prime, and not to differ from an unrelated letter prime. As we will see, the results of Experiment 1 do not fit this prediction. In a second experiment, we test a very different account of diacritic priming. According to this account, a diacritic is a visual feature diagnostic of letter identity, and the asymmetric pattern of diacritic priming has little to do with its linguistic function, but is explained in terms of general properties of visual object recognition. We will introduce this explanation after Experiment 1, and test it in Experiment 2.

In designing our experiment, we made two methodological changes to the previous diacritic priming studies. The first was that rather than presenting the prime in lowercase and target in uppercase (e.g., $\grave{a}-A ; o-O$ ), we presented primes and targets in the same kana form (katakana). Presenting the prime in lowercase and the target in uppercase is a standard practice that originated in the masked priming lexical decision task developed by Forster and Davis (1984), but neither Chetail and Boursain (2019) or Perea et al. (2019) gave a strong rationale for adopting the convention in their experiments. In fact, the 
presentation of prime and target in different case creates an interpretative challenge for these studies, because of the five vowel letters used, two were cross-case dissimilar $(a / A, e / E)$, and three were cross-case similar $(\mathrm{i} / \mathrm{I}, o / O, u / U)$. It is unclear therefore how much the visual similarity of letters contributed to the diacritic priming effect in these studies. (We will return to a discussion of this issue after Experiment 1.) There are also other theoretical and practical reasons for preferring the presentation of prime and target in the same case. Foremost is that the research question addressed by the present and previous diacritic priming studies is whether the letters with a diacritic (e.g., $\hat{a}$ ) is recognized as a variant of the base letter (e.g., a) or a separate letter identity. This question is more directly addressed by using the prime and target that contain the same base form, distinguished only by the presence/absence of diacritic (e.g., $\hat{a}-a ; a-\hat{a})$ - that is, by presenting the prime and target in the same case. Second, for scripts without the uppercase/lowercase distinction like Arabic, this is the only way to conduct the experiment (e.g., Perea, Abu Mallouh, Mohammed, Khalifa, \& Carreiras, 2016). For scripts where different case format exists, the use of same-case prime and target would maintain comparability with scripts like Arabic. For these reasons, we suggest that as the first step, it is preferable to conduct diacritic priming experiments with the prime and target presented in the same case, rather than with the prime and target presented in different case, with a mix of cross-case similar (e.g., $o-O$ ) and cross-case dissimilar (e.g., $\grave{a}-A$ ) letter pairs, as has been the case in previous studies.

The second departure from the previous studies was the use of the letter match task instead of the alphabet decision task. It has been pointed out by Arguin and Bub (1995) that the alphabet decision task can be performed without unique letter identification, and hence priming in this task may be insensitive to letter identity. In fact, at the prime duration of $50 \mathrm{~ms}$, the authors were unable to detect a statistical difference in the size of priming effect produced by the physically identical prime (e.g., $A-A$ ), nominally identical prime (e.g., $a-A$ ), a visually similar letter prime (e.g., $C-G, E-F$ ), and a dissimilar prime (e.g., $A-M, B-N$ ), although they were all faster than the nonletter (an asterisk) prime (e.g., ${ }^{*}-A$ ) condition. Arguin and Bub (1995) concluded from this that the alphabet decision task is "performed through a response selection process that disregards the specific identity to which the activation corresponds" (p. 1204) and that the priming effect in this task largely reflects response priming. A related issue is that the size of priming in the alphabet decision task is small: Even the (nominal) identity priming effect ( $a-A$ vs. $z-A$ ), which sets the upper limit to the size of priming (Forster, Mohan, \& Hector, 2003), is about $20 \mathrm{~ms}$ (it was $17 \mathrm{~ms}$ in Chetail \& Boursain's, 2019, in Experiment 1a and $23 \mathrm{~ms}$ in Experiment 1b; and $21 \mathrm{~ms}$ in Perea et al., 2019). For these reasons, Kinoshita and Kaplan (2008) have advocated the use of the letter match task ("Is the target letter the same as the referent letter?") to investigate letter priming effects in lieu of the alphabet decision task. Unlike the alphabet decision task, the letter match task necessarily requires unique letter identification, and hence priming in this task is sensitive to letter identity (see Norris \& Kinoshita, 2008); it produces much larger priming effects (the identity priming effect in this task usually exceeds $50 \mathrm{~ms}$ ); and it is particularly suited to testing priming of a small set of stimuli that are used repeatedly in an experiment, as it is free of the stimulus-response mapping effects that could dominate priming in the alphabet decision task (see Kinoshita \& Kaplan, 2008, for a detailed explanation). Accordingly, this is the task we will use in our study.

We now turn to a description of diacritics in the Japanese kana syllabary to explain the predicted pattern of data according to the linguistic function hypothesis.

\section{Japanese kana}

Japanese text is written using two distinct writing systems, logographic kanji and the kana syllabary, and diacritics are used only in the latter. There are two parallel allographic forms of kana - hiragana and katakana - and the properties we describe below apply to both hiragana and katakana. Each kana character denotes a mora, a syllable-like phonological unit composed of either a single vowel or a consonantvowel combination (and a nasal consonant mora, $/ \mathrm{n} /$, which cannot be word-initial). Unlike the alphabetic system, there is no distinction between "letter names" (e.g., "tee" for $t$ or $T$ ) and "letter sounds" (the phoneme/t/); the mora serves as both. For each mora, there is a corresponding kana: For example, ケ is the katakana character for the mora $/ \mathrm{ke} /$.

Of the 46 basic kana characters, 20 can be combined with a diacritic. All 20 base form kana without a diacritic denote unvoiced obstruent consonant-vowel morae (e.g., 力 $/ \mathrm{ka} /$; 又 /su/), and the diacritic mark changes the phonemic value of the consonant component of the mora. The dakuten diacritic (which looks like a double apostrophe, placed in the top right-hand corner above the basic kana) indicates voicing, and is used with kana letters with the initial $/ \mathrm{k} /, / \mathrm{s} /, / \mathrm{t} /, / \mathrm{h} /$ morae turning them into $/ \mathrm{g} /, \mathrm{z} /, / \mathrm{d} /($ or $/ \mathrm{dz} /)$ and $/ \mathrm{b} /$ initials e.g., カ $(/ \mathrm{ka} /)$-> ガ $(/ \mathrm{ga} /)$; ス $(/ \mathrm{su} /)$-> ズ (/zu/). The handakuten diacritic (a small circle placed in the top right-hand corner above the basic kana) is used with kanas with the initial $/ \mathrm{h} /$ morae, turning them into initial $/ \mathrm{p} /$ morae e.g., 八 (/ha/) -> ハi (/pa/);へ/he $->ヘ 0 / p e /$. Table 1 presents the exhaustive set of diacritic katakana letters and their base kana counterparts. ${ }^{3}$

\footnotetext{
${ }^{3}$ Of the 20 base kana letters, $千$ (/chi/) and $ッ(/$ tsu/), when combined with the diacritic, produce kana corresponding to the morae $/ \mathrm{ji} /$ and $/ \mathrm{zu} /$, which are homophonic with the morae corresponding to $シ$ and $゙$, respectively, and the former diacritic kana are rarely used in contemporary Japanese text (and not shown in the table). We therefore used only 18 of the base kana letters, and their diacritic counterparts in Experiment 1.
} 
Table 1 The list of kana letters used and their roman transcription

\begin{tabular}{|c|c|c|c|c|c|c|c|c|c|}
\hline \multicolumn{5}{|c|}{ Base letter } & \multicolumn{5}{|c|}{ Letter with diacritics } \\
\hline $\begin{array}{l}\text { 力 } \\
/ \mathrm{ka} /\end{array}$ & $\begin{array}{l}\neq \\
/ \mathrm{ki} /\end{array}$ & $\begin{array}{l}ク \\
/ \mathrm{ku} /\end{array}$ & $\begin{array}{l}\text { ケ } \\
/ \mathrm{ke} /\end{array}$ & $\begin{array}{l}コ \\
\text { /ko/ }\end{array}$ & $\begin{array}{l}\text { ガ } \\
\text { /ga/ }\end{array}$ & $\begin{array}{l}\text { ギ } \\
\text { /gi/ }\end{array}$ & $\begin{array}{l}ク ゙ \\
/ \mathrm{gu} /\end{array}$ & $\begin{array}{l}ケ ゙ \\
/ \mathrm{ge} /\end{array}$ & $\begin{array}{l}\text { ゴ } \\
/ \mathrm{go} /\end{array}$ \\
\hline $\begin{array}{l}+ \\
/ \mathrm{sa} /\end{array}$ & $\begin{array}{l}\text { シ } \\
\text { /shi/ }\end{array}$ & $\begin{array}{l}\text { ᄌ } \\
/ \mathrm{su} /\end{array}$ & $\begin{array}{l}セ \\
/ \mathrm{se} /\end{array}$ & $\begin{array}{l}\text { Y } \\
\text { /so/ }\end{array}$ & $\begin{array}{l}サ ゙ \\
\text { /za/ }\end{array}$ & $\begin{array}{l}シ \\
\text { /ji// }\end{array}$ & $\begin{array}{l}\text { ズ } \\
\mid \mathrm{zu} /\end{array}$ & $\begin{array}{l}セ ゙ \\
\text { /ze/ }\end{array}$ & $\begin{array}{l}\text { ゾ } \\
\text { /zo/ }\end{array}$ \\
\hline $\begin{array}{l}\text { 夕 } \\
/ \mathrm{ta} /\end{array}$ & $\begin{array}{l}\text { チ }^{\mathrm{a}} \\
/ \mathrm{chi} /\end{array}$ & $\begin{array}{l}ッ^{\mathrm{a}} \\
/ \mathrm{tsu} /\end{array}$ & $\begin{array}{l}\text { テ } \\
/ \mathrm{te} /\end{array}$ & $\begin{array}{l}\text { 卜 } \\
/ \mathrm{to} /\end{array}$ & $\begin{array}{l}\text { 夕゙ } \\
/ \mathrm{da} /\end{array}$ & & & $\begin{array}{l}\text { デ } \\
/ \mathrm{de} /\end{array}$ & $\begin{array}{l}\text { ド } \\
/ \mathrm{do} /\end{array}$ \\
\hline $\begin{array}{l}\text { 八 } \\
\text { /ha/ }\end{array}$ & $\begin{array}{l}t \\
/ \mathrm{hi} /\end{array}$ & $\begin{array}{l}7 \\
/ \mathrm{hu} /\end{array}$ & $\widehat{\widehat{h e} /}$ & $\begin{array}{l}\text { 木 } \\
\text { /ho/ }\end{array}$ & $\begin{array}{l}\text { バ/ } \\
\mathrm{ba} / \\
\text { パ } \\
/ \mathrm{pa} /\end{array}$ & $\begin{array}{l}\text { ビ } \\
/ \mathrm{bi} / \\
ヒ^{\circ} \\
/ \mathrm{pi} /\end{array}$ & $\begin{array}{l}\text { ブ/ } \\
\mathrm{bu} / \\
フ^{\circ} \\
/ \mathrm{pu} /\end{array}$ & $\begin{array}{l}\text { べ } \\
/ \mathrm{be} / \\
\text { ぺ } \\
/ \mathrm{pe} /\end{array}$ & $\begin{array}{l}\text { ボ/bo } \\
\text { ポ } \\
/ \mathrm{po} /\end{array}$ \\
\hline
\end{tabular}

${ }^{\text {a }}$ As explained in Footnote 2, these two base kana letters were not used as stimuli, because their diacritic counterparts (not shown) are homophonous with ジ $(/ \mathrm{ji} /)$ and $ス ゙(/ \mathrm{zu} /)$ and are not used in contemporary Japanese text

It should be clear from the above description that kana with and without diacritics denote different morae. They also have different letter names, and further, the presence/absence of a diacritic creates a lexical contrast (e.g., ガス/ga.su/, “gas” vs. カス /ka.su/, "scum”). These properties of kana with diacritics mean that they should function as "not mere variants of their base letters but . . . unitary elements of the script in their own right" (Chetail \& Boursain, 2019, p. 347). Thus, according to the view that linguistic function of the diacritic determines the pattern of priming - as argued by both Chetail and Boursain (2019) and Perea et al. (2019) — the same pattern of priming effects as those observed with the vowel letters with and without accents in French and not like Spanish are expected for Japanese kana. Experiment 1 tests this prediction.

\section{Experiment 1}

The design of Experiment 1 was similar to that of Perea et al. (2019), and the prime type manipulation (identity prime, the diacritic prime, and the unrelated letter prime) was crossed with the target kana type manipulation (kana with vs. without a diacritic). For the reasons explained above, we presented the prime and the target in the same kana form (we used kataka$\mathrm{na}^{4}$ ), and used the letter match task instead of the alphabet decision task used in the previous studies. The results expected from the linguistic function hypothesis is that the Japanese kana letters should show the same pattern of priming as French and different from Spanish, as the kana with and without diacritics are different letter identities.

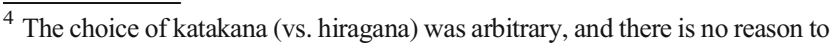
expect the pattern of diacritic priming to be different with hiragana.
}

\section{Method}

Participants Thirty-one students (10 males, mean age $=23.7$ years, $S D=5.9$ years) from Hiroshima University participated in the experiment in return for 500 yen (US\$4.40). All were native speakers and readers of Japanese and had normal or corrected-to-normal vision.

Design The task was a masked priming letter match task, in which participants decided whether a single kana letter target (e.g., カ, /ka/; ガ, /ga/) matched the referent letter. The target was preceded by a briefly presented prime letter, one of three prime types: (1) identity, (2) diacritic, and (3) unrelated. This was crossed with the target kana type factor (diacritic-present vs. diacritic-absent). The dependent variables were response latency and error rate.

Materials The critical stimuli were 41 katakana letters (18 base letters without a diacritic and 23 letters with a diacritic), which constituted the exhaustive set of kana that are distinguished by the presence/absence of diacritics (see Table 1). Each kana was paired with three types of primes: (1) identity: the same kana as the target (e.g., カ - カ [/ka/ - / ka/]; ガ - ガ [/ga/-/ga/]); (2) diacritic: the kana distinguished by the presence/absence of diacritic (e.g., ガ - カ [/ga/ - / ka/]; カ - カ [ $/ \mathrm{ka} /-/ \mathrm{ga} /]$ ); and (3) unrelated: a different kana that shared the diacritic status with the target (e.g., サーカ $[/ \mathrm{sa} /-/ \mathrm{ka} /]$; ザ - ガ [/za/-/ga/]). Each prime-target pair was presented once in the "same" response condition (41 targets $\times 3$ prime conditions $=123$ trials), and once in the "different" response condition (123 trials), resulting in 246 trials in total. In the "same" condition, the referent was the same kana as the target; in the "different" condition, the referent was one of the other kana matched with the target kana on the diacritic status that was different from the prime and the target (e.g., referent: シ, prime: 力 [identity]/ ガ [diacritic]/サ[unrelated], target: 力).

Apparatus and procedure Participants were tested individually, seated approximately $60 \mathrm{~cm}$ in front of a computer monitor upon which stimuli were presented. The letter match task contained 246 test trials, presented in two blocks with a selfpaced break between them. Each block contained an equal number of same and different trials, and a representative number of trials from the three prime conditions, and a different random order of trials was generated for each participant. A practice block of 20 trials, using characters not used in the test trials preceded the test block.

Stimulus presentation and data collection were achieved through the use of the DMDX display system (Forster \& Forster, 2003). Stimulus display was synchronized to the screen refresh rate $(16.7 \mathrm{~ms})$.

Participants were instructed at the outset of the experiment that they would be presented with two katakana characters in 
succession, and their task was to decide whether the two were the same. They were instructed to press the right shift key for the same response and the left shift key for the different response. Each trial started with the presentation of a reference character presented above a forward mask consisting of three \# signs, for $500 \mathrm{~ms}$. The reference character then disappeared, and at the same time the forward mask was replaced by the prime for $50 \mathrm{~ms}$, followed immediately by a target. The target was presented in the same font (Hiragino Maru Gothic) as the referent and the prime, and magnified 1.2 times to avoid physical overlap. Targets were presented for a maximum of 2,000 $\mathrm{ms}$, or until the participant's response. Participants were given an error feedback (a red "X") when an error was made.

\section{Results}

The "same" trials from the letter match task were analyzed. The data are based on 31 participants and 41 kana as stimuli (3,813 data points).

Correct RTs and error rates were analyzed using linear mixed-effects (LME) modelling with subjects and stimuli as crossed random factors (Baayen, 2008), using the packages lme4 (Version 1.1-17; Bates, Maechler, Bolker, \& Walker, 2018), and lmerTest (Version 3.0-1; Kuznetsova, Brockhoff, \& Christensen, 2018) implemented in R (Version 3.5.1, 201807-02; R Core Team, 2018), according to the following general procedure. The fixed effect factors were prime condition (referenced to the diacritic prime condition) and the letter type (referenced to the kana without a diacritic). In the analysis of RTs, error trials were excluded, and the RTs were logtransformed to meet the distributional assumptions of LME. Upon the inspection of Q-Q plot, data points with RT slower than a cutoff were excluded as outliers. We tested linear mixed-effects models with random slopes and random intercepts and simplified the structure if the model did not converge or the model fit was not improved by model complexity. The raw data and the analysis file from this study can be found on the Open Science Framework (https: osf.io/6ahy7/). The mean correct RT and error rates are shown in Table 2.
RT In the analysis of RTs, 173 error trials (4.5\%) were excluded, as well as two slow outliers ( 2 data points with RT slower than $1,500 \mathrm{~ms}$ ), resulting in 3,638 data points for analysis.

The final statistical model we report here included as the fixed factor prime type (referenced to the diacritic prime condition), and letter type (contrast-coded $-.5, .5$ ) and a random slope for Primetype and random intercept for subjects: $\operatorname{logRT}$ $\sim$ Primetype $\times$ Lettertype $+(1 \mid$ item $)+($ Primetype $\mid$ subj $)$. The effect of letter type was significant, $t=-5.323, B=-.070, S E$ $=.013, p<.001$, with faster response to kana with a diacritic (when preceded by a diacritic prime). Relative to the diacritic prime condition, identity prime condition was significantly faster, $t=-5.206, B=-.045, S E=.008, p<.001$, and the unrelated letter prime condition was significantly slower, $t=$ $13.766, B=.143, S E=.010, p<.001$. These priming effects interacted with letter type: The difference between the identity prime and the diacritic prime was significantly greater for the $\mathrm{D}-$ letter, $t=-3.72, B=.061, S E=.016, p<.001$; conversely, the difference between the unrelated prime and the diacritic prime was significantly greater for the D+ letter, $t=-6.938, B$ $=.016, S E=.017, p<.001$. In other words, the pattern of priming produced by a diacritic prime was asymmetrical, with the $\mathrm{D}-$ prime facilitating the recognition of $\mathrm{D}+$ letter more than the converse.

To quantify the relative amount of evidence for the Letter type $\times$ Prime Type interaction, Bayes factor was calculated using the BayesFactor package (Version 0.9.12-4.1; Morey \& Rouder, 2018) comparing the model including the interaction as the denominator and the model without the interaction as the numerator. A Bayes factor is an odds ratio, with 1 indicating equal evidence for the two alternative hypotheses, and odds of 3 or greater generally considered to provide "some evidence," greater than 10 to be "strong evidence," and odds greater than 30 to be "very strong evidence" (Dienes, 2014; Jeffreys, 1961). The Bayes factor was over 94 million, indicating an overwhelming amount of evidence for the interaction (asymmetric pattern of priming).

Follow-up analyses tested priming effects with the kana targets with and without diacritics separately. For the kana

Table 2 Mean response times, in ms, and percentage error rates $(\% \mathrm{E})$ in parentheses, for the "same" response conditions in Experiment 1

\begin{tabular}{|c|c|c|c|c|}
\hline \multirow[b]{3}{*}{ Prime condition } & \multicolumn{4}{|c|}{ Target kana type } \\
\hline & \multicolumn{2}{|c|}{ Diacritic absent (e.g., 力 /ka/) } & \multicolumn{2}{|c|}{ Diacritic present (e.g., ガ/ga/) } \\
\hline & Example & $\mathrm{RT}(\% \mathrm{E})$ & Example & RT $(\% \mathrm{E})$ \\
\hline Identity & 力 $/ \mathrm{ka} /$ & $419(1.8)$ & ガ/ga/ & $415(2.8)$ \\
\hline Diacritic & ガ/ga/ & $451(2.9)$ & 力 $/ \mathrm{ka} /$ & $421(2.7)$ \\
\hline Unrelated & $+/ \mathrm{sa} /$ & $491(5.9)$ & バ/ba/ & $514(10.5)$ \\
\hline Diacritic-Identity & & $32(1.1)$ & & $6(-0.1)$ \\
\hline Unrelated-Diacritic & & $40(3.0)$ & & $93(7.8)$ \\
\hline
\end{tabular}


targets with a diacritic, the diacritic prime produced as much facilitation as the identity prime, $t=-1.319, B=-.014, S E=$ $.011, p=.187$, and more than the control prime, $t=-17.739, B$ $=.200, S E=.011, p<.001$. For the kana targets without a diacritic, the diacritic prime produced less priming than the identity prime, $t=-6.239, B=-.075, S E=.012, p<.001$, and more than the control prime, $t=-7.000, B=.086, S E=.012, p$ $<.001$. These patterns were identical to that reported by Perea et al. (2019) with the Spanish stimuli.

\section{Error rate}

Error rates were analyzed with generalized linear mixedeffects models with subjects and stimuli as crossed random factors, using the logit function appropriate for categorical variables (Jaeger, 2008). The model tested was: Error rate Lettertype $\times$ Primetype $+(1 \mid$ item $)+(1 \mid$ subject $)$. As for RT, the Letter type factor was contrast-coded, and the Primetype factor was referenced to the diacritic prime. The only significant effect was the difference between the diacritic prime condition and the unrelated letter prime condition, $Z=5.57, p<$ .001 . Error rates generally mirrored the pattern for RTs.

\section{Discussion}

The results were clear. When the target kana did not contain a diacritic, the priming produced by a diacritic prime was less than that produced by the identity prime, but more than the unrelated control letter prime (カーカくガーカくサーカ); with the letter with a diacritic as the target, a diacritic prime pro-

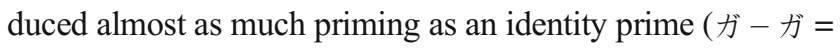
カガくバーガ). These kana priming data replicate the pattern observed by Perea et al. (2019) with the vowel letters with and without diacritic (accent marks) in Spanish: $(a-A<\dot{a}-A<\dot{e}-A$ and $\dot{a}-\dot{A}=a-\dot{A}<e-\dot{A})$. This is despite the fact that the linguistic function served by the diacritic are very different for Japanese kana and Spanish vowel letters, with the diacritic in Japanese kana but not in Spanish vowel letters changing the segmental value, providing lexical contrast, and having a different letter name. ${ }^{5}$ The results are therefore inconsistent with the linguistic function hypothesis. Additionally, we note that

\footnotetext{
5 The results for the kana targets without a diacritic are also similar to those reported by Chetail and Boursain (2019) with vowel letters in French $(a-A<$ $\dot{a}-A=z-A$ ), except for the difference between the diacritic prime and the unrelated control prime. In Footnote 2, we noted that the absence of the difference in the French study but not in the Spanish study may have been because as the unrelated prime, Chetail and Boursain (2019) used letters without a diacritic, whereas Perea et al. (2019) used letters with a diacritic (e.g., é). Here, (like the French study), the unrelated primes did not contain a diacritic, but the diacritic prime facilitated target recognition more than the unrelated prime. It is possible that the failure to detect a difference between a diacritic prime and an unrelated prime in the French study may have been due to the use of the alphabet decision task which, as we noted in the introduction, yields small priming effects overall and hence limits the opportunity for detecting differences between prime conditions.
}

more recently Marcet, Ghukasyan, Fernández-López, and Perea et al. (2020) reported a lexical decision experiment using Spanish words that contain the letters $n$ and $\tilde{n}$ (e.g., casino, señora). Unlike the vowel letters with and without accents in Spanish, the letters $n$ and $\tilde{n}$ provide lexical contrast; however, the results showed the same pattern of asymmetric diacritic priming - for example, e.g., casino-CASINO < casiño-CASINO = casiso-CASINO, but señora-SEÑORA $=$ senora-SEÑORA $<$ sesona-SEÑORA. These results are entirely consistent with our Experiment 1 with Japanese kana letters with and without a diacritic, and add to the evidence against the linguistic function hypothesis.

In sum, Japanese kana, like Spanish vowel letters and Spanish consonant letters, showed an asymmetric pattern of diacritic priming, with a $\mathrm{D}+$ prime producing a smaller facilitation of $\mathrm{D}^{-}$target than a $\mathrm{D}-$ prime priming a $\mathrm{D}+$ target. We now consider an alternative explanation of the pattern of diacritic priming effects in terms of visual similarity, framed within the "noisy channel" theory of letter/word recognition (Norris \& Kinoshita, 2012a).

\section{The role of visual similarity in the priming of letter representations}

Letters with diacritics (e.g., é, è) are visually very similar to the base letter (e.g., e). In the visual similarity rating data collected by Simpson, Mousikou, Montoya, and Defior (2013), the letters with diacritics have the highest similarity rating to the base letter: For example, on a scale of 1-7, with 7 being maximally similar (i.e., identical), the rated similarity between the base letter $e$ and the diacritic variants $(\dot{e}, \grave{e}, \hat{e}$, and $\ddot{e})$ are all above 6.0 , unmatched by the similarity rating between two visually similar, but different letters (e.g., the similarity rating between $e$ and $c$ is 4.43 ).

Chetail and Boursain (2019) noted this "huge visual overlap between a diacritic letter and its base letter" and considered the possibility that this "may lead readers to process the two written stimuli as variants of the same letter" (p. 348). However, later in the General Discussion, they argued that like the letters with and without diacritics, some of the letters of the alphabet (e.g., $e$ and $c$ ) also have a high degree of visual overlap, "yet nobody would question the existence of distinct abstract identity representations for visual inputs such as $e$ and $c$ " (p. 351). The implicit assumption here seems to be that masked priming by different letter identities is independent of the visual similarity between the prime letter and the target letter (e.g., priming of the letter $e$ by the letter $c$ is no greater than letter $z$ ). However, as we explain below, there are theoretical and empirical reasons to question this assumption.

Kinoshita, Robidoux, Mills, and Norris (Kinoshita, Robidoux, Mills, \& Norris, 2014) pointed out that it is important to distinguish between two types of visual similarity 
manipulation: one is between different letter identities (as in e and c), and the other is between allograph variants that map onto the same letter (as in A and a). For the latter, there is much empirical and theoretical consensus that priming is independent of similarity of form: Across a number of studies, it has been shown that the visual similarity of allograph prime (e.g., a/A, $g / G, r / R$, are visually dissimilar; $c / C, x / X, v / V$, are visually similar) does not modulate the size of identity priming, for words (e.g., Bowers, Vigliocco, \& Haan, 1998), pseudowords (Kinoshita \& Norris, 2009, Experiment 2), and single letters in a cross-case letter match (e.g., Kinoshita \& Kaplan, 2008; Norris \& Kinoshita, 2008). The defining feature of allographs is that although they can vary in their similarity, the different forms map onto the same letter identity, that is, they are tokens of the same letter type. Here, the visual similarity of the prime-target letter pairs has no impact on the size of priming (i.e., $a-A$ vs. $r-A=c-C$ vs. $x-C$ ).

This, however, does not mean that visual similarity of different letter identities (as in e and c) does not impact on priming. To the extent that letter identity is defined by its shape (visual features), and visual perception is noisy, early on during letter and word perception the letter identity is ambiguous, and a visually similar prime facilitates letter identification than a visually dissimilar prime (Kinoshita et al., 2014). There is much empirical support for this view. One line of evidence comes from "leet" priming effects (Perea, Duñabeitia, \& Carreiras, 2008): A word prime in which letters are substituted by digits that resemble the letter (e.g., M4T3R14LMATERIAL) primes a word almost as much as an identity prime, and more than a control prime in which the letters are substituted by visually dissimilar digits or letters (e.g., M6T2R76L, MOTURUOL). Kinoshita and Lagoutaris (2010) extended this finding to single letters (e.g., $\# 4 \%$ \#A\% $<\# 6 \%$ \#A\%), indicating that leet priming effects are not limited to letters presented in the context of a word.

Perea and colleagues (e.g., Gutiérrez-Sigut, Marcet, \& Perea, 2019; Marcet \& Perea, 2017) have also reported that substituted-letter priming in lexical decision is greater for visually similar letters $(u-v ; i-j)$ than for dissimilar letters $(u-z$; $i-g$ ) (e.g., nevtral-NEUTRAL < neztral-NEUTRAL; dentjsta-DENTISTA $<$ dentgsta-DENTISTA). ${ }^{6}$ This should extend to diacritic priming: To the extent that a letter with a

\footnotetext{
${ }^{6}$ In contrast to these studies, Kinoshita et al. (2014) had more limited success in demonstrating visual similarity effects with substituted-letter primes presented in uppercase and target presented in lowercase (e.g., HRHNDONabandon $=$ DWDNDON-abandon. However, as pointed out by Marcet and Perea (2017), there was a small numerical trend, and the failure to find a significant visual similarity priming effect may have been due to lack of power (in Kinoshita et al., 2014, there were 740 data points per cell, whereas in Marcet \& Perea, 217, there were 2,160 data points per cell.). It is worth noting that Kinoshita et al. did find a statistically significant visual similarity priming effect with "leet" primes (e.g., 484NDON-abandon < 676NDON-abandon), and their focus was on explaining the dissociation between leet priming and letter priming.
}

diacritic is visually very similar to the base letter, it would be expected that the diacritic prime should function like a visually similar letter. In labelling their diacritic prime and unrelated control prime condition "visually similar" and "visually dissimilar" condition, Perea et al. (2019) anticipated the greater priming produced by diacritic primes relative to the unrelated control primes based on visual similarity.

What is not explained by this visual similarity view of diacritic priming, however, is the asymmetry in diacritic priming. Recall that both in the present Experiment 1 with Japanese kana and in the experiment with Spanish (Perea et al., 2019), when the target was a letter with a diacritic (D+ letter), a letter without a diacritic ( $\mathrm{D}-$ letter) produced priming as large as an identity prime (e.g., ガーガ カカーガ; $\dot{a}-\dot{A}=a$ $\dot{A}$ ), whereas when the target was a letter without a diacritic (D - letter), a letter with a diacritic (D+ letter) produced priming that was much smaller than the identity prime (e.g., カーカ< ガ - カ; $a-A<\dot{a}-A$ ). In most models of word/letter recognition, similarity is taken to be symmetric - $e$ is as similar to $c$ as $c$ is to $e$. (This symmetry assumption is reflected in how letter similarity ratings are represented, where the data above/below the diagonal are assumed to be redundant.) If so, how could the asymmetry in priming arise?

Norris and Kinoshita (2012a) proposed that reading is best explained as a process of decoding perceptual information that has passed through a noisy channel. The concept of the noisy channel was first introduced by Shannon (1948). A noisy communication channel may corrupt the signal in different ways. For example, it could delete some component of the signal, or it could insert spurious information. In order to maximize transmission of information through a communication channel the process responsible for decoding must be optimized to take account of the properties of the channel. For example, in many electronic communication systems, information is transmitted as a sequence of packets. Noise can lead to packet loss, but is unlikely to result in the appearance of a packet that was not actually transmitted. Here, we assume that the same is true of visual perception and that visual features are more likely to be lost than inserted. If the uppercase letter $E$ is transmitted through such a channel and the received features correspond to $F$, then an optimal decoder will assume that there is some probability that the transmitted letter was actually $E$. In contrast, if the letter $F$ is transmitted, it is highly unlikely that the channel would insert the exact feature required to output the letter $E$. Inserting part of an $S$ or a $P$ would not generate an $E$. The noisy channel therefore introduces an asymmetry: Something that looks like an $F$ might have been an $E$, but something that looks like an $E$ almost certainly was not an $F$.

Norris and Kinoshita (2012a) themselves did not test empirically the properties of visual perception system to see whether it is more likely to delete than insert a visual feature, or vice versa. However, extant evidence from Treisman and 
Souther's (Treisman \& Souther, 1985; see also Treisman \& Gormican, 1988) search asymmetry experiments suggests that early vision more readily detects the presence of a feature than its absence. In a series of search experiments requiring the detection of a target distinguished from the distractors by a single feature, the authors found that when the target had the feature that was absent in the distractors (e.g., target $Q$ amongst the distractor $O$ ) the target popped out, whereas when the target lacked the feature that was present in the distractors (e.g., the target $O$ amongst the distractor $Q$ ) the search was slow, and serial. The asymmetric pattern of diacritic priming fits this pattern: With a letter without a diacritic (D- letter) as the target, the presence of a diacritic (D+ letter prime) functioned like a different letter (e.g., カーカくガ - カ; $a-A<\dot{a}-$ $A)$, whereas with a letter with a diacritic (D+ letter) as the target, the diacritic-absent prime ( $\mathrm{D}$ - letter prime) functioned like an identity prime (e.g., ガーガ =カーガ; $a-\dot{A}=\dot{a}-\dot{A}$ ).

In Experiment 2, we test this account of priming asymmetry using letters of the Latin alphabet that are visually similar and are distinguished by the presence/absence of a feature (e.g., $O$ and $Q, F$ and $E$ ). If the asymmetric pattern of priming by letters with and without diacritics is due to the property of the noisy channel (the visual perception system) which treats the diacritic as a visual feature of a letter, we expect the same asymmetry to be observed between these different letter identities. Specifically, we expect the priming of "feature-present" target by a "feature-absent" prime to be greater, and more like the identity prime (e.g., $E-E=F-E)$ than the converse $(F-F<$ $E-F)$.

\section{Experiment 2}

\section{Method}

Participants Seventeen students (three males, mean age $=$ 19.88 years, $S D=4.47$ years) from Macquarie University participated in the experiment in return for course credit. All were native speakers and readers of English and had normal or corrected-to-normal vision.

Design The task was a masked priming letter match task. The independent variables were target letter type (distinguishing feature present vs. absent) and prime type (identity, similar). The dependent variables were response latency and error rate.

Materials The critical stimuli were four pairs of uppercase letters of the Latin alphabet, $E-F, P-R, C-G$, and $O-Q$. Each member of a pair was distinguished by the presence/ absence of a single feature (e.g., the bottom horizontal line segment present in $E$ and absent in $F$ ). Each letter was paired with an identity prime (e.g., $E-E ; F-F$ ) or a similar prime (e.g., $E-F ; F-E$ ). The prime and target were presented in
Courier New font, and to avoid physical overlap, the target was magnified 1.2 times. Each prime-target pair was repeated 8 times in the "same" response condition and 8 times in the "different" response condition, resulting in 128 "same" trials ( 8 target letter $\times 2$ prime conditions $\times 8$ repetition) and 128 "different" trials, a total of 256 trials. In the "same" condition, the referent was the same letter as the target; in the "different" condition, the referent was one of the other letters dissimilar to the target or the prime (e.g., referent: $O$, prime: $F / E$, target: $F$ ).

Apparatus and procedure The apparatus and the general procedure were identical to those in Experiment 1.

\section{Results}

The "same" trials from the letter match task were analyzed. The data are based on 17 participants and eight letters as stimuli (2,176 data points).

Correct RTs and error rates were analyzed using linear mixed effects (LME) modelling, similarly to that in Experiment 1. The raw data and the analysis file from this study can be found on the Open Science Framework (osf.io/ 6ahy7/). The mean correct RT and error rates are shown in Table 3.

\section{RT}

In the analysis of RTs, 120 error trials (5.5\%) were excluded, as well as five slow outliers ( 5 data points with RT slower than $1,500 \mathrm{~ms}$ ), resulting in 2,051 data points for analysis.

The final statistical model we report here included prime type (referenced to the similar prime condition) and letter type (contrast coded $-.5, .5$ ) as fixed effect factors and a random slope for Primetype and random intercept for subjects and random intercept for items: $\operatorname{logRT} \sim$ Primetype $\times$ Lettertype $+(1 \mid$ item $)+($ Primetype $\mid$ subj $)$. The effect of Letter type was significant, $t=-4.067, B=-.069, S E=.017, p<.001$, with faster response to letters with the feature present (e.g., $Q, E$ ) when preceded by a similar letter prime. The prime type effect was significant, $t=-6.591, B=-.079, S E=.012, p<.001$,

Table 3 Mean response times, in $\mathrm{ms}$, and percentage error rates (\%) in parentheses, for the "same" response conditions in Experiment 2

\begin{tabular}{|c|c|c|c|c|}
\hline \multirow[t]{3}{*}{ Prime condition } & \multicolumn{4}{|c|}{ Target letter type } \\
\hline & \multicolumn{2}{|c|}{ Feature absent (e.g., $O$ ) } & \multicolumn{2}{|c|}{ Feature present (e.g., $Q$ ) } \\
\hline & Example & $\mathrm{RT}(\% \mathrm{E})$ & Example & $\mathrm{RT}(\% \mathrm{E})$ \\
\hline Identity & $O$ & $468(4.0)$ & $Q$ & $484(6.4)$ \\
\hline Similar & $Q$ & $531(6.1)$ & $O$ & $493(5.5)$ \\
\hline Similar-Identity & & $63(2.1)$ & & $9(-.9)$ \\
\hline
\end{tabular}

Note. The letter pairs were $O-Q, F-E, P-R$, and $C-G$ 
with the identity prime condition being faster than the similar prime condition. The prime type factor interacted with letter type, $t=4.808, B=.098, S E=.020, p<.001$ : The difference between the identity prime and the diacritic prime was significantly greater for the feature-absent target. The Bayes factor for the interaction was 5,917, indicating an overwhelming amount of evidence for the interaction (asymmetric pattern of priming).

Follow-up analysis tested the priming effect for the letter targets with the feature present and the feature absent, separately. For the feature-present targets (e.g., $Q, E$ ), the difference between the similar prime and the identity prime conditions did not reach statistical significance, $t=-1.968, B=$ $-.030, S E=.015, p=.066$. The Bayes factor for this effect was .6, indicating relatively more (albeit ambiguous) support for the null difference. For the feature-absent targets (e.g., $O$, $F$ ), the identity prime produced more priming than the similar prime, $t=-5.121, B=-.127, S E=.024, p<.001$. The Bayes factor for this effect was 9 , indicating strong support for the difference.

Error rate Error rates were analyzed with generalized linear mixed-effects models with subjects and stimuli as crossed random factors, using the logit function appropriate for categorical variables (Jaeger, 2008). The model tested was: Error rate $\sim$ Lettertype $\times$ Primetype $+(1 \mid$ item $)+(1 \mid$ subject $)$. As for RT, the Letter type factor was contrast-coded, and the Primetype factor was referenced to the similar prime. None of the main or interaction effects reached significance, all $|Z|$ $<, 1.589, p>.112$. Error rates were generally low, and there was little variability between conditions.

\section{Discussion}

The results of Experiment 2 using pairs of visually similar uppercase letters of the Latin alphabet that are distinguished by the presence/absence of a feature (e.g., $O / Q ; F / E$ ) paralleled the asymmetry in priming with the letter pairs distinguished by the presence/absence of a diacritic observed in the present Experiment 1, and by Perea et al. (Perea et al., 2019; and also, Marcet, Ghukasyan, Fernández-López, \& Perea, 2020, in a lexical decision task). Specifically, for targets containing the distinguishing feature (e.g., $Q, E$ ), a visually similar letter prime that lacked the feature (e.g., $O, F$ ) produced priming that was indistinguishable from an identity prime (e.g., $Q-Q=O-Q$ ); whereas for targets lacking the distinguishing feature, a visually similar prime containing the feature produced less priming than the identity prime (e.g., $O-O<Q-O$ ). To the extent that a diacritic is a distinguishing visual feature, just as a line segment is a feature that distinguishes between different letter identities (e.g., $O$ vs. $Q ; F$ vs. $E$ ), we take the result as evidence that that the asymmetric pattern of diacritic priming has its origin in visual perception, the "noisy channel" that forms the front end of visual letter/word recognition (Norris \& Kinoshita, 2012a).

We should note that the concept of asymmetric similarity is not a novel idea. Tversky (1977) discussed the directionality of similarity as applied to a variety of contexts, including semantic similarity in similes (e.g., people say "Turks fight like tigers" but not "Tigers fight like Turks") and metaphors (e.g., a poet would say "My love is as deep as the ocean," not "Tthe ocean is as deep as my love"). Recently, Perea et al. (2020) appealed to Tversky (1977) to explain why their earlier lexical decision experiment did not show priming by vowel primes containing a diacritic (e.g., féliz did not facilitate the recognition of FELIZ ["happy" in Spanish] any more than the control prime fáliz). According to Perea et al. (2020) the finding is explained by "a general theory of asymmetrical similarities in which 'asymmetry is explained by the relative salience of the stimuli' (Tversky, 1977, p. 337) so that a less salient stimulus is more similar to the more salient stimulus than vice versa" (p. 6). Although there is clearly a commonality between Tversky's (1977) and Norris and Kinoshita's (2012) notions of asymmetric similarity, and there is much to be learned from Tversky's theory of similarity relation, we are a little more circumspect than Perea et al. (2020) in appealing to Tversky's "general theory of asymmetrical similarity" to explain the priming asymmetry observed with letter identification. In the absence of independent definition of salience, explaining the similarity priming asymmetry in terms of "relative salience" simply shifts the burden of explanation (what makes the accented vowel letter $e ́$ more salient than $e$ ? the letter $Q$ more salient than letter $O$ ? the letter $G$ more salient than $C$ ? etc.), and it has little predictive power. Norris and Kinoshita's (2012a) proposal was intended to be specific to perceptual similarity, rooted in the core assumption of the noisy channel model that regards "reading as a process of recovering a signal being transmitted through a noisy channel" (p. 518) where the noisy channel is human visual perception. It is the characteristics of basic processes of visual object recognition that guide the identification of letter identity and letter order.

Returning to the parallels between diacritical markers and other visual features that distinguish between letters, it is relevant to note that Perea et al. (2016) conducted a masked priming lexical decision experiment in Arabic, concluding, similar to the present view, that diacritical information serves as a distinguishing visual feature. An important property of Arabic script is that many of the 28 Arabic letters share the basic shape (called "rasm" in Arabic) with at least one letter, so that they only differ in the number or location of diacritic marks (e.g.,

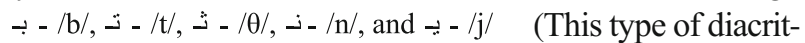
ic is referred to as consonant pointing, called "i'jam" in Arabic, and is one of the numerous types of diacritics in Arabic. Consonant pointing is not optional, unlike the other types of diacritics, which indicate, for instance, short vowels, called 
"harakāt".) In a design similar to the diacritic priming experiment conducted by Chetail and Boursain (2019), three types of primes preceded the targets: (1) identity, (2) diacritic (in which a root letter was substituted with a another letter sharing the same basic shape and differed in the number of diacritic points), and (3) unrelated control (in which the critical letter was substituted with another letter with a different basic shape). Their results showed a sizable advantage for the identity condition over the two substituted letter conditions, which did not differ from each other, resembling the French lexical decision data reported by Chetail and Boursain (2019) (taper-TAPER < tâper-TAPER = tuper-TAPER). What is important to note about the design of Perea et al.'s experiment is that the diacritic prime sometimes contained the distinguishing diacritic that was absent in the target, and in other cases, the diacritic prime did not contain the distinguishing diacritic that was present in the target, and in other cases, the diacritic prime and the target differed in the number of distinguishing diacritics, and the analysis did not separate these cases. Given the finding of the present experiments, it would be of interest to see if an asymmetric pattern of priming emerges when these cases are analyzed separately.

\section{Conclusion}

Previous masked priming studies conducted with French and Spanish vowel letters have yielded different patterns of priming, leading to the view that whether letters with a diacritic (e.g., $\hat{a})$ are recognized as a variant of the base letter $(a)$, or as a separate letter identity, depends on the linguistic functions served by diacritics in different languages. Here, we tested diacritic priming with Japanese katakana. Our results mirrored those observed with Spanish, despite the very different linguistic function served by diacritics in the two languages, and showed that the kana prime without a diacritic (e.g., 力, $/ \mathrm{ka} /$ ) facilitated the recognition of the kana with a diacritic (ガ, /ga/) almost as much as the identity prime (e.g., ガ, /ga/), whereas a kana prime with a diacritic (e.g., ガ, /ga/) produced a much smaller facilitation than the identity prime. We tested, and found, support for an explanation of this asymmetry based on the noisy channel model (Norris \& Kinoshita, 2012a), according to which the asymmetry arises from a property of early vision, which more readily detects the presence of a feature than its absence in distinguishing between otherwise identical stimuli (cf. Treisman \& Souther, 1985).

When describing the varying linguistic function served by diacritics across languages, Protopapas and Gerakaki (2009) noted that "although letters with diacritics are often treated as separate letters for lexicographic purposes, they may be treated as variants of the same letter perceptually" (p. 454, emphasis added). In line with this, we found little evidence that the shared versus separate identity of a letter with a diacritic is determined by the language-specific function of the diacritic. We have argued elsewhere that "the basic perceptual processes supporting the identification of written symbols are universals, and are governed by exactly the same principles as all other forms of visual object recognition" (Norris \& Kinoshita, 2012b, p. 297). This perspective has served well as a framework for studying the processing of orthographic representations (coding of letter identity and letter order) across different languages and scripts (e.g., Kinoshita, Norris, \& Siegelman, 2012; Kinoshita \& Verdonschot, 2019), and letters with diacritics seem to be no exception.

\section{References}

Adelman, J. S. (2011). Letters in time and retinotopic space. Psychological Review, 118, 570-582. https://doi.org/10.1037/ a0024811

Arguin, M., \& Bub, D. (1995). Priming and response selection processes in letter classification and identification tasks. Journal of Experimental Psychology: Human Perception and Performance, 21, 1199-1219.

Baayen, R. H. (2008). Analyzing linguistic data: A practical introduction to statistics using $R$. Cambridge: Cambridge University Press.

Bates, D. M, Maechler, M., Bolker, B., \& Walker, S. (2018). Lme4: Linear mixed-effects models using 'eigen' and S4 (Version 1.117) [Computer software].

Bowers, J. S., Vigliocco, G., \& Haan, R. (1998). Orthographic, phonological, and articulatory contributions to masked letter and word priming. Journal of Experimental Psychology: Human Perception and Performance, 24, 1705-1719. https://doi.org/10.1037/00961523.24.6.1705

Chetail, F., \& Boursain, E. (2019). Shared or separated representations for letters with diacritics? Psychonomic Bulletin \& Review, 26, 347352.

Davis, C. J. (2010). The spatial coding model of visual word identification. Psychological Review, 117, 713-758. https://doi.org/10.1037/ a0019738

Dehaene, S. (2009). Reading in the brain: The science and evolution of a human invention. New York: Penguin Viking.

Dienes, Z. (2014). Using Bayes to get the most out of non-significant results. Frontiers in Psychology, 5, 781.

Forster, K. I., \& Davis, C. (1984). Repetition priming and frequency attenuation in lexical access. Journal of Experimental Psychology: Learning, Memory and Cognition, 10, 680-698.

Forster, K. I., \& Forster, J. C. (2003). DMDX: A Windows display program with millisecond accuracy. Behavior Research Methods Instruments and Computers, 35, 116-124.

Forster, K. I., Mohan, K., \& Hector, J. (2003). The mechanics of masked priming. In S. Kinoshita \& S. J. Lupker (Eds.), Masked priming: The state of the art (pp. 3-38). New York: Psychology Press.

Frost, R. (2012). Towards a universal model of reading. Behavioral and Brain Sciences, 35, 263-329. https://doi.org/10.1017/ S0140525X11001841

Gutiérrez-Sigut, E., Marcet, A., \& Perea, M. (2019). Tracking the time course of letter visual-similarity effects during word recognition: A masked priming ERP investigation. Cognitive, Affective, \& Behavioral Neuroscience, 1-19. Advance online publication. https://doi.org/10.3758/s13415-019-00696-1 
Jaeger, T. F. (2008). Categorical data analysis: Away from ANOVAs (transformation or not) and towards logit mixed models. Journal of Memory and Language, 59, 434-446.

Jeffreys, H. (1961). Theory of probability (3rd ed.). Oxford: Oxford University Press.

Kinoshita, S., \& Kaplan, L. (2008). Priming of abstract letter identities in the letter match task. Quarterly Journal of Experimental Psychology, 61, 1873-1885. https://doi.org/10.1080/ 17470210701781114

Kinoshita, S., \& Lagoutaris, S. (2010). Priming by NUMB3R5 does not involve top-down feedback. Journal of Experimental Psychology: Learning, Memory and Cognition, 36, 1422-1440.

Kinoshita, S., Norris, D., \& Siegelman, N. (2012). Transposed-letter priming in Hebrew in the same-different task. Quarterly Journal of Experimental Psychology, 65, 1296-1305.

Kinoshita, S., Robidoux, S., Mills, L., \& Norris, D. (2014). Visual similarity effects on masked priming. Memory \& Cognition, 42, 821833. https://doi.org/10.3758/s13421-013-0388-4

Kinoshita, S., \& Verdonschot, R. (2019). On recognizing Japanese katakana words: Explaining the reduced priming with hiragana and mixed-kana identity primes. Journal of Experimental Psychology: Human Perception and Performance, 45, 1513-1521.

Kuznetsova, A., Brockhoff, P. B., \& Christensen, R. H. B. (2018). lmerTest: Tests in linear mixed effects models (Version 3.0-1) [Computer software]. Retrieved from http://CRAN.R-project.org/ package $=$ lmerTest

Marcet, A., Ghukasyan, H., Fernández-López, M., \& Perea, M. (2020). Jalapeno or jalapeño: Do diacritics in consonant letters modulate visual similarity effects during word recognition? Applied Psycholinguistics, 41(3), 579-593. https://doi.org/10.1017/ S0142716420000090

Marcet, A., \& Perea, M. (2017). Is nevtral NEUTRAL? Visual similarity effects in the early phases of written-word recognition. Psychonomic Bulletin \& Review, 24, 1180-1185. https://doi.org/10.3758/s13423016-1180-9

Morey, R. D., \& Rouder, J. N. (2018). BayesFactor: Computation of Bayes factors for common designs (R Package Version 0.9.12-4.1) [Computer software]. Retrieved from http://CRAN.R-project.org/ package $=$ BayesFactor

Norris, D., \& Kinoshita, S. (2008). Perception as evidence accumulation and Bayesian inference: Insights from masked priming. Journal of Experimental Psychology: General, 137, 434-455. https://doi.org/ 10.1037/a0012799

Norris, D. \& Kinoshita, S. (2012a). Reading through a noisy channel: Why there's nothing special about the perception of orthography. Psychological Review, 119, 517-545.

Norris, D., \& Kinoshita, S. (2012b). Orthographic processing is universal; it's what you do with it that's different. Invited commentary on Frost: Towards a universal model of reading. Behavioral and
Brain Sciences, 35, 296-297. https://doi.org/10.1017/ S0140525X11001841

Perea, M., Abu Mallouh, R., Mohammed, A., Khalifa, B. \& Carreiras, M. (2016). Do diacritical marks play a role at the early stages of word recognition in Arabic? Frontiers in Psychology, 7, 1255. https://doi. org/10.3389/fpsyg.2016.01255

Perea, M., Baciero, A., \& Marcet, A. (2020). Does a mark make a difference? Visual similarity effects with accented vowels Psychological Research. Advance online publication https://doi.org/10.1007/ s00426-020-01405-1

Perea, M., Duñabeitia, J. A., \& Carreiras, M. (2008). R34D1NG W0RD5 W1TH NUMB3R5. Journal of Experimental Psychology: Human Perception and Performance, 34, 237-241. https://doi.org/10.1037/ 0096-1523.34.1.237

Perea, M., Fernández-López, M., \& Marcet, A. (2019). What is the letter é? Scientific Studies of Reading. Advance online publication. https:// doi.org/10.1080/10888438.2019.1689570

Protopapas, A., \& Gerakaki, S. (2009). Development of processing stress diacritics in reading Greek. Scientific Studies of Reading, 13, 453483. https://doi.org/10.1080/10888430903034788

R Core Team. (2018). R: A language and environment for statistical computing [Computer software]. Vienna: R Foundation for Statistical Computing. Retrieved from http://www.R-project.org/

Shannon, C. E. (1948). A mathematical model of communication [Electronic version]. The Bell System Technical Journal, 27, 279423.

Simpson, I. C., Mousikou, P., Montoya, J. M., \& Defior, S. (2013). A letter visual-similarity matrix for Latin-based alphabets. Behavioral Research Methods, 45, 431-439. https://doi.org/10.3758/s13428012-0271-4

Treisman, A., \& Gormican, S. (1988). Feature analysis in early vision: Evidence from search asymmetries. Psychological Review, 95, 1548.

Treisman, A., \& Souther, J. (1985). Search asymmetry: A diagnostic for preattentive processing of separable features. Journal of Experimental Psychology: General, 114, 285-310.

Tversky, A. (1977). Features of similarity. Psychological Review, 84, 327-352. https://doi.org/10.1037/0033-295x.84.4.327

Open practices statement The data file and the output of the statistical analysis from this study can be found on the Open Science Framework (https://osf.io/6ahy7/). Neither of the experiments reported here were preregistered.

Publisher's note Springer Nature remains neutral with regard to jurisdictional claims in published maps and institutional affiliations. 